\title{
PENERAPAN ANALISIS KONJOIN DALAM PENILAIAN DOSEN FMIPA TERHADAP PEMBUKAAN PROGRAM STUDI STATISTIKA DI UNIVERSITAS PATTIMURA
}

\author{
Salmon N. Aulele ${ }^{*}$, Helda Y. Taihuttu ${ }^{2}$, Mozart W. Talakua ${ }^{3}$ \\ 1,2,3 Jurusan Matematika, Fakultas MIPA, Universitas Pattimura \\ Jln. Ir. M. Putuhena, Kampus Unpatti, Poka-Ambon, 97233, Indonesia \\ e-mail: ${ }^{*}$ salmon.aulele@yahoo.com ; ${ }^{2}$ edhalisya.en@gmail.com ; ${ }^{3}$ ocat_08@yahoo.com
}

Corresponding Author *

\begin{abstract}
Abstrak
Analisis konjoin adalah salah satu analisis statistik multivariat yang dapat digunakan untuk mengetahui keadaan suatu produk atau jasa. Pada penelitian ini analisis konjoin diterapkan untuk mengetahui penilaian dosen terhadap pembukaan program studi statistika di universitas pattimura. Atribut yang perlu diperhatikan yaitu jumlah dosen, banyaknya ruangan kuliah, peminat program studi, kondisi laboratorim, kondisi perpustakan, dan pengguna lulusan. Data diperoleh dari 50 dosen FMIPA. Hasil penelitian ini diketahui bahwa keadaan Program Studi Statistika nantinya memiliki karakteristik dosen statistika cukup, ruangan kuliah kurang, peminat program studi banyak, kondisi laboratorium baik, kondisi perpustakaan dan pengguna lulusan banyak dan menurut pendapat dosen FMIPA atribut yang sangat perlu diperhatikan adalah atribut jumlah dosen
\end{abstract}

Kata Kunci : Analisis Konjoin, Penilaian Dosen, Program Studi Statistika

\section{APPLICATION OF KONJOIN ANALYSIS IN LECTURER FMIPA ASSESSMENT ON THE OPENING OF STATISTICS STUDY PROGRAM IN PATTIMURA UNIVERSITY}

\begin{abstract}
Conjoint analysis is one multivariate statistical analysis that can be used to know the condition of a product or service. In this research, conjoint analysis is applied to know the lecturer's evaluation on the opening of Statistics Program Study of university in pattimura. Atributes that need to be considered are the number of lecturers, number of lecture rooms, study program applicants, laboratory conditions, library conditions, and graduate users. Data were obtained from 50 lecturers of FMIPA. The results of this study are known to be statistically statistically consistent lecturers, less lecture rooms, many study program enthusiasts, good laboratory conditions, library conditions and many graduate users and in the opinion of FMIPA lecturers atribut hich is worth noting is the attribute of the number of lecturers.
\end{abstract}

Keywords : Conjoint Analysis, Lecturer Assessment, Statistics Study Program 


\section{PENDAHULUAN}

Peningkatan Sumber Daya Manusia di era global menuntut standardisasi kompetensi keahlian dan akademik yang kompetitif. Perguruaan tinggi diharapkan mampu berperan menghasilkan lulusan yang berkualitas dan dapat menyesuaikan diri dengan berbagai perubahan yang terjadi. Dalam menyikapi hal ini Fakultas Matematika dan Ilmu Pengetahuan Alam (FMIPA) Universitas Pattimura (UNPATTI) meresponi melalui pembukaan Program Studi Statistika.

Upaya pembukaan Program Studi Statistika perlu memperhatikan berbagai atribut berdirinya suatu Program Studi. Atribut yang perlu diperhatikan yaitu jumlah dosen, banyaknya ruangan kuliah, peminat program studi, kondisi laboratorim, kondisi perpustakan, dan pengguna lulusan. Tingkat kepentingan setiap atribut perlu diperhatikan untuk mengatisipasi kekurangan-kekurangan dari Program Studi. Jika ada atribut yang kurang maka harus dipenuhi demi kelancaran proses belajar mengajar. Atribut dan level atribut akan menunjukan keadaan Program Studi Statistika yang nantinya dibuka.

Adapun salah satu metode statistika yang dapat digunakan untuk menyelesaikan permasalahan adalah Analisis Konjoin. Analisis konjoin adalah salah satu analisis statistik multivariat yang dapat digunakan untuk mendapatkan kombinasi atau komposisi atribut-atribut suatu produk sehingga dapat dievaluasi keadaan suatu produk atau jasa. Analisis konjoin juga mampu menjelaskaan konsep baru dan karakteristik suatu produk atau jasa. Pada penelitian ini peneliti mengambil judul "Penerapan Analisis Konjoin Untuk Menilai Pembukaan Program Studi Statistika di Universitas Pattimura”[5].

\section{TINJAUAN PUSTAKA}

\subsection{Analisis Konjoin}

\section{Definisi Analisis Konjoin}

Analisis konjoin adalah sebuah teknik analisis yang dapat digunakan untuk menentukan tingkat kepentingan relatif berdasarkan persepsi pelanggan yang dibawa oleh suatu produk tertentu dan nilai kegunaan yang muncul dari atribut-atribut produk terkait [3]. Analisis konjoin digunakan untuk mengetahui bagaimana penilaian seseorang terhadap satu objek/jasa. Analisis konjoin dapat diekspresikan dalam model :

$$
Y_{i}=X_{1}+X_{2}+\cdots+X_{n}
$$

Keterangan :

$\begin{array}{cl}Y_{i} & =\text { berupa data non metrik atau metrik } \\ X_{1}+X_{2}+\cdots+X_{n} & =\text { berupa data non metrik }\end{array}$

\section{Proses Dasar Analisis Konjoin}

Ada beberapa tahapan dalam merancang dan melaksanakan analisis konjoin secara umum adalah sebagai berikut[1]:

1. Merumuskan Masalah

Merumuskan masalah dalam hal ini peneliti mengidentifikasi atribut dan level yang dipilih haruslah sangat penting.

2. Membentuk Stimuli

Setelah peneliti menetapkan atribut dan level atribut peneliti perlu mengkombinasikan antara atribut dengan level. Kombinasi antara atribut dengan level disebut Stimuli

3. Menentukan Penilaian Responden

Kombinasi antara atribut dan level yang ada kemudian di jalankan untuk mengumpulkan pendapat responden terhadap setiap stimuli.

4. Memilih Suatu Prosedur analisis konjoin.

Model dasar analisis konjoin dirumuskan secara matematis sebagai berikut :

$$
U(x)=\sum_{i=1}^{m} \sum_{j=1}^{k_{i}} a_{i j} x_{i j}
$$


Keterangan:

$U(x):$ Seluruh utility dari suatu alternative

$a_{i j} \quad$ : Sumbangan the part-worth atau utility taraf ke- $j$ atribut ke- $i$

$k_{i} \quad$ : Banyaknya level atribut ke- $i$

$m$ : Banyaknya atribut

$x_{i j} \quad$ : Dummy variable. atribut ke-taraf ke-j bernilai 1, kalau level ke $j$ dari atribut ke $i$ terjadi, kalau tidak terjadi $\mathrm{n}$ bernilai 0 .

Pentingnya suatu atribut, misalnya $I_{i}$, didefinisikan, dinyatakan dalam kisaran part-worth yaitu:

$$
I_{i}=\left\{\max \left(a_{i j}\right)-\min \left(a_{i j}\right)\right\} \text {, untuk setiap } i .
$$

Pentingnya atribut, dinormalkan (normalized) untuk meyakinkan kepentingan relatifnya dengan atribut lainnya

$$
w_{i}=\frac{I_{i}}{\sum_{i=1}^{m} I_{i}} \times 100 \%
$$

Ket:

$w_{i}=$ Pentingnya atribut (factor importance) ke- $i$

$I_{i}=$ Range nilai kepentingan untuk tiap atribut

5. Interpretasi Hasil

Interpretasi hasil ini dilakukan pada semua tingkat kepentingan atribut sesuai nilai yang ada.

\subsection{Menghitung Ketepatan Prediksi}

Dalam menguji ketepatan prediksi dalam analisis konjoin dilakukan dengan korelasi pearson's $R$ dan Tau Kendal.

$H_{0}$ : Tidak ada hubungan yang kuat antara estimasi dengan observasi.

$H_{1}$ : Ada hubungan yang kuat antara estimasi dengan observasi.

Kriteria Pengambilan keputusan:

Jika probabilitas (sig) $>0,05$ maka $H_{0}$ diterima.

Jika probabilitas (sig) $<0,05$ maka $H_{1}$ diterima.

\subsection{Uji Validitas dan Reliabilitas}

\section{Uji Validitas}

Uji validitas adalah suatu ukuran yang menunjukkan tingkat-tingkat kevalidan atau kesahihan sesuatu instrumen [4].

$$
r_{x y}=\frac{n \sum x y-\sum x \sum y}{\sqrt{\left\{\left(n \sum x^{2}\right)-(x)^{2}\right\}\left\{\left(n \sum y^{2}\right)-\left(\sum y\right)^{2}\right\}}}
$$

Keterangan:

$$
\begin{array}{ll}
r_{x y} & : \text { Koefisien korelasi } \\
X & : \text { Skor pertanyaan untuk setiap subjek } \\
y & : \text { Skor total } \\
x y & : \text { Skor pertanyaan dan skor total } \\
n & : \text { Jumlah sampel }
\end{array}
$$

Kriteria pengambilan keputusan :

Jika r-hitung > r-tabel, maka butir pernyataan dinyatakan valid.

Jika r-hitung $<$ r-tabel, maka butir pernyataan dinyatakan tidak valid.

\section{Uji Reliabilitasi}

Hasil penelitian yang reliabel, bila terdapat kesamaan data dalam waktu yang berbeda[2]. Uji reliabilitasi juga dapat digunakan untuk mengukur suatu kuesioner. Uji reliabilitas dengan memelihara koefisien $\alpha$-cronbach menggunakan rumus sebagai berikut : 


$$
\alpha=\left(\frac{k}{k-1}\right)\left(\frac{1-\sum \sigma_{i}^{2}}{\sigma_{i}^{2}}\right)
$$

Keterangan :

$\alpha \quad$ : Kkeandalan alpha-cronbach

$\sigma_{i}^{2} \quad$ : Varian total

$\sum \sigma_{i}^{2}:$ Jumlah varian butir

$k \quad$ : Banyaknya butir pertanyaan

Kriteria pengambilan keputusan:

Jika nilai Cronbach's Alpha> 0,6 maka dinyatakan reliabel.

Jika nilai Cronbach's Alpha $<0,6$ maka dinyatakan tidak reliabel.

\section{METODE PENELITIAN}

Data yang digunakan dalam penelitian ini adalah data primer yang diperoleh dengan mengambil sampel sebagian dari Dosen FMIPA Universitas Pattimura. Bahan yang digunakan dalam penelitian ini diperoleh dengan menggunakan kuesioner yang dibagikan kepada Dosen FMIPA secara random. Atribut dan level atribut :

1) Dosen, jumlah dosen banyak, kurang dan sedikit.

2) Ruangan, ruang kuliah yang dapat digunakan untuk perkuliahan banyak dan kurang.

3) Peminat, peminat program studi statistik banyak dan kurang.

4) Laboratorium, kondisi laboratorium baik dan buruk.

5) Perpustakaan, kondisi perpustakaan baik dan buruk.

6) Pengguna lulusan, pengguna lulusan statistika di dunia kerja banyak, cukup, dan sedikit.

\section{HASIL DAN PEMBAHASAN}

Bagian ini membahas tentang pengumpulan data dan pengolahan data. Pada bagian pengumpulan data akan dijelaskanmengenai tahapan kuesioner untuk mengetahui penilaian pembukaan program studi statistika. Sedangkan pada bagian pengolahan data akan dijelaskan tahapan pengolahan data dari kuesioner dengan menggunakan analisis konjoin SPSS 23 dan interprestasi hasilnya. Pengumpulan data dilakukan untuk mendaptkan informasi penilaian dosen FMIPA terhadap pembukaan program studi statistika pada jurusan matematika.

\subsection{Mendesain Stimuli}

Tabel 1. Kombinasi Atribut dan Level Atribut

\begin{tabular}{|lll|}
\hline \multicolumn{1}{|c}{ Atribut } & Taraf & \multicolumn{1}{c|}{ Level } \\
\hline \multirow{3}{*}{ Dosen } & 1 & Banyak \\
\cline { 2 - 3 } & 2 & Cukup \\
\hline \multirow{2}{*}{ Ruangan } & 3 & Kurang \\
\cline { 2 - 3 } Peminat & 1 & Banyak \\
\cline { 2 - 3 } & 2 & Kurang \\
\hline \multirow{2}{*}{ Laboratorium } & 1 & Banyak \\
\hline \multirow{2}{*}{ Perpustakaan } & 2 & Kurang \\
\cline { 2 - 3 } & 2 & Baik \\
\hline \multirow{2}{*}{ Pengguna } & 1 & Buruk \\
\cline { 2 - 3 } & 2 & Buruk \\
\cline { 2 - 3 } & 2 & Banyak \\
\cline { 2 - 3 } & 3 & Cukup \\
\hline
\end{tabular}

Berdasarkan Tabel 1, jika dikombinasikan secara manual $3 \times 2 \times 2 \times 2 \times 2 \times 3=144$, stimuli. Stimuli yang terlalu banyak akan menyulitkan responden dalam meminilai sebanyak 144 stimuli. Perlu 
mengurangi jumlah kombinasi sebanyak 144 menjadi lebih sedikit untuk itu dibuat dalam syntax SPSS. Hasil sintax dapat dilihat sebagai berikut.

Tabel 2. Hasil pembuatan Stimuli

\begin{tabular}{|ccccccc|}
\hline Card & Dosen & Ruangan & Peminat & Lab & Perpustakaan & Pengguna \\
\hline 1 & Cukup & Banyak & Banyak & Buruk & Buruk & Sedikit \\
\hline 2 & Banyak & Cukup & Kurang & Buruk & Buruk & Sedikit \\
\hline 3 & Banyak & Cukup & Kurang & Baik & Buruk & Cukup \\
\hline 4 & Banyak & Banyak & Kurang & Baik & Buruk & Banyak \\
\hline 5 & Cukup & Cukup & Kurang & Buruk & Baik & Banyak \\
\hline 6 & Cukup & Cukup & Kurang & Buruk & Baik & Banyak \\
\hline 7 & Banyak & Banyak & Banyak & Buruk & Baik & Banyak \\
\hline 8 & Kurang & Cukup & Banyak & Buruk & Buruk & Banyak \\
\hline 9 & Kurang & Banyak & Kurang & Baik & Baik & Sedikit \\
\hline 10 & Banyak & Cukup & Banyak & Baik & Baik & Sedikit \\
\hline 11 & Banyak & Banyak & Kurang & Buruk & Buruk & Banyak \\
\hline 12 & Banyak & Cukup & Banyak & Buruk & Baik & Cukup \\
\hline 13 & Kurang & Banyak & Kurang & Buruk & Baik & Cukup \\
\hline 14 & Banyak & Banyak & Banyak & Baik & Baik & Banyak \\
\hline 15 & Kurang & Cukup & Banyak & Baik & Buruk & Banyak \\
\hline 16 & Cukup & Banyak & Banyak & Baik & Buruk & Cukup \\
\hline
\end{tabular}

Berdasarkan Tabel 2, setiap stimuli dapat menjelaskan masing-masing kombinasi antara atribut dan level. contohnya pada stimuli pertama menjelaskan jumlah dosen cukup, ruangan kuliah banyak, peminat program studi banyak, kondisi laboratorium buruk, kondisi perpustakaan buruk, pengguna lulusan sedikit. Setersunya sampai stimuli ke-16 masing-masing dengan penjelasannya.

\subsection{Nilai utiliti dan Nilai Kepentingan Relatif.}

Nilai utiliti dapat menjelaskan tingkat penilaian responden terhadap atribut dan level atribut yang ada.

Tabel 3. Nilai Utiliti

\begin{tabular}{|ccr|}
\hline \multirow{2}{*}{ Atribut } & Level & $\begin{array}{c}\text { Nilai } \\
\text { Utiliti }\end{array}$ \\
\hline \multirow{2}{*}{ Dosen } & Banyak & $-0,103$ \\
\cline { 2 - 3 } & Cukup & 0,152 \\
\cline { 2 - 3 } & Kurang & $-0,048$ \\
\hline \multirow{2}{*}{ Ruangan } & Banyak & $-0,098$ \\
\cline { 2 - 3 } & Kurang & 0,098 \\
\hline \multirow{2}{*}{ Peminat } & Banyak & 0,08 \\
\cline { 2 - 3 } & Kurang & $-0,08$ \\
\hline \multirow{2}{*}{ Lab } & Baik & 0,027 \\
\cline { 2 - 3 } & Kurang & $-0,027$ \\
\hline \multirow{2}{*}{ Perpus } & Baik & 0,105 \\
\cline { 2 - 3 } & Kurang & $-0,105$ \\
\hline \multirow{2}{*}{ Pengguna } & Banyak & 0,043 \\
\cline { 2 - 3 } & Cukup & $-0,002$ \\
\cline { 2 - 3 } & Sedikit & $-0,042$ \\
\hline
\end{tabular}

Berdasarkan Tabel 3, dapat dilihat nilai kepentingan setiap atribut yang paling diperhatikan dosen FMIPA adalah jumlah dosen cukup dengan nilai utiliti sebesar 0,152, atribut ruangan kuliah kurang dengan nilai utiliti 0,098, atribut peminat program studi banyak dengan nilai utiliti 0,08 , atribut kondisi laboratorium baik dengan nila utiliti 0,027 atribut kondisi perpustakaan baik dengan nilai utiliti 0,105 dan atribut pengguna lulusan banyak dengan nilai utiliti 0,043.

Nilai kepentingan relatif merupakan tingkat presentase dari masing-masing atribut. 
Tabel 4. Nilai Kepentingan Relatif

\begin{tabular}{|lc|}
\hline \multicolumn{1}{|c|}{ Atribut } & $\begin{array}{c}\text { Nilai } \\
\text { Kepentingan }\end{array}$ \\
\hline Dosen & 25,308 \\
\hline Ruangan & 13,787 \\
\hline Peminat & 13,397 \\
\hline Laboratorium & 11,871 \\
\hline Perpustakaan & 13,864 \\
\hline Pengguna & 21,773 \\
\hline
\end{tabular}

Berdasarkan Tabel 4, nilai kepentingan dapat menjelaskan bahwa dari keenam atribut yang paling diperhatikan oleh responden (dosen) adalah jumlah dosen dengan presentasi sebesar 25,308\%, kemudian pengguna lulusan $21,773 \%$, ruangan $13,787 \%$, perpustakaan $13,864 \%$, peminat $13,397 \%$ dan laboratorium $11,871 \%$.

\subsection{Menghitung Ketepatan Prediksi}

Menghitung ketepatan prediksi bertujuan untuk mengetahui adanya korelasi dan signifikan antara hasil estimasi dan hasil aktual.

Tabel 5. Hasil Ketepatan Prediksi

\begin{tabular}{|ccc|}
\hline & Value & Sig. \\
\hline Pearson's R & 0,654 & 0,003 \\
\hline Kendall's tau & 0,565 & 0,001 \\
\hline
\end{tabular}

Berdasarkan Tabel 5, dapat menjelaskan untuk pengukuran korelasi secara pearson's maupun kendall nilai signifikan $<0,05$ artinya ada korelasi yang kuat antara hasil estimasi dan data aktual.

\section{KESIMPULAN}

Dari hasil analisa data dan pembahasan dapat diperoleh kesimpulan sebagai berikut :

1. Keadaan Program Studi Statistika nantinya memiliki jumlah dosen cukup, ruangan kuliah kurang, peminat program studi banyak, kondisi laboratorium baik, kondisi perpustakaan baik dan pengguna lulusan banyak.

2. Menurut penilaian dosen FMIPA urutan kepentingan atribut yang perlu diperhatikan dalam pembukaan program studi statistika adalah jumlah dosen menjadi prioritas utama seterusnya diikuti oleh atribut pengguna lulusan, ruangan kuliah, perpustakaan, peminat program studi dan laboratorium.

\section{DAFTAR PUSTAKA}

[1] Amelia, A., Rais, dan Nur'eni, Analisis Konjoin Untuk Preferensi Mahasiswa Matematika Fmipa Universitas Tadulako dalam memilih Handphone (HP), Online Jurnal Of Natural Science, pp. 56-64, 2015.

[2] P. Astuti, Pengaruh Event Marketing terhadap Keputusan Pembelian Produk Rokok Envio Mild (Survei Pada Konsumen Bisnis Mitra Usaha PT. Djarum di Kab.Bandung), Universitas Pendidikan Indonesia |repository.upi.edu |perpustakaan.upi.edu., 2013.

[3] Khrisna, Analisis konjoin http://datariset.com/analisis/detail/olah-data-jogja-contjoint-analysis., 2013.

[4] P. D. M, Pengaruh Sumber Belajar Terhadap Prestasi Belajar Siswa Pada Mata Pelajaran Akuntansi Universitas Pendidikan Indonesia, repository.upi.edu, perpustakaan.upi.edu., 2013.

[5] M. Y. Matdoan, E. R. Persulessy, F. Kondolembang, Pengukuran Preferensi Pelanggan PT. PLN (Persero) Dalam Menentukan Atribut Rekening Listrik Prabayar di Kota Ambon dengan Menggunakana Analisis Konjoin, Jurnal Barekeng Universitas Pattimura., 2016. 